\title{
Teaching Students to Design and Commercialize New Products: A Journey in its Third Decade
}

\author{
Daniel Forbes (University of Minnesota, Carlson School of Management)
}

KEYWORDS: Professional, Scientific, Technical Services, Educational Services, Entrepreneurship, Innovation, Product Development, Technology Commercialization, student entrepreneurs, Student innovators.

Entrepreneurship education takes a variety of forms. In recent years, many colleges and universities have shown an interest in educational experiences that are both "cross-campus" and "experiential." Cross-campus initiatives bring together students and faculty from different schools who might not otherwise interact. Experiential initiatives, meanwhile, create opportunities for students to learn by engaging in entrepreneurial activity, as opposed to simply studying it.

For over 20 years, the University of Minnesota has run a cross-campus, experiential course devoted to the design and commercialization of new products. The course, called, "New product design and business development" (NPDBD), is administered jointly by the College of Science \& Engineering and the Carlson School of Management. This article summarizes some key features of that course as well as some "lessons learned" by the faculty who have led it.

\section{An overview of the NPDBD course}

The primary aim of the course is to give graduate students in engineering and business an opportunity to acquire the knowledge and skills associated with developing and commercializing a new product. A secondary aim is to help sponsoring companies move new product ideas closer to a successful launch. Both aims are served by having students complete real, new product development projects for companies in exchange for a sponsorship fee.

In a typical year, the course takes on six projects, each of which is assigned to a team of six students. Enrollment at any one time, therefore, is around 36 students, with roughly half being graduate students in engineering and the other half being MBA students. In addition, each of the six teams is assigned a "coach,"

typically an expert drawn from the university faculty or a pool of trusted local executives. Coaches meet regularly with their teams and help them manage a demanding schedule of assignments, client meetings, and similar deliverables. To help protect the sponsors' intellectual property, all students and coaches sign non-disclosure agreements for all six projects.

Because the course works closely with students and faculty in mechanical engineering, projects typically involve medical devices, industrial products and household or consumer products. Historically the course has not taken on food products, soft goods (e.g., textiles), or intangible products such as software or services, since developing these products calls for knowledge and processes that fall outside the course's domain. One "success story" that has emerged from the course is the "Post-It Note Pen," which our students helped develop for the 3M Corporation and which is still sold in stores today.

A short video about the course can be viewed at this site(https://www.youtube.com/watch?v=sVAgRwCltAg)

\section{How the course works}

The course meets once weekly for three hours. The first half of this period is devoted to some combination of lecture and in-class activities designed to introduce students to key elements of the processes involved in designing and commercializing a new product. The exact sequence of lessons varies from year to year, but it typically involves attention to lessons that fall on both the "technical side" and the "market side" of the innovation process (https://eiexchange.com/content/205-how-can-wedefine-innovation) . 
For example, students receive instruction in sketching, prototyping and patent research, as well as in how to define and explore alternative product markets using "voice of the customer" techniques. The lessons follow a general trajectory that leads from a relatively openended identification of customer needs (in the early Fall) to the development of a more detailed business plan (in the late Spring). But since the design process is iterative, many activities recur throughout the year, and most teams do not progress in a linear fashion.

The sponsors are often established companies, which are charged a sponsorship fee of $\$ 25,000$, and in some cases startups firms and solo entrepreneurs, which pay a reduced fee of $\$ 10,000$. These fees support the extra costs of running the course, which include fees paid to project coaches (most of whom do not receive teaching credits for their involvement) as well as expenses for prototyping, supplies, and technical support.

A summary of the benefits that accrue to participating students and sponsors can be viewed at this site (https://carlsonschool.umn.edu/departments/strategic-m anagement-entrepreneurship-department/academicprograms/new-product-design) .

We require students to purchase a textbook for the course: Product Design and Development (https://www.amazon.com/dp/B00ZYY672W/ref=cm_s w_r_cp_ep_dp_j19GzbPMNVCWF) by Karl Ulrich and Steven Eppinger, which is currently in its 6th edition. Chapters are assigned throughout the year, but they serve primarily as "background information" in connection with various topics. Exams, problem sets, and conventional term papers are not part of this course. In general, students are evaluated based on team assignments that are due throughout the year and align closely with the deliverables provided to clients. Assignments are reviewed by the course instructors and coaches and returned to the teams with detailed feedback - usually within one week of the submission date.

\section{Lessons learned}

The NPDBD course has been offered at the University of Minnesota since Fall 1994. A few core faculty have been involved throughout that time, including Profs. Will Durfee and Art Erdman of the Department of Mechanical Engineering. Other faculty have rotated into and out of the course over the years. (I joined as a coinstructor in 2014.) Here are a few of the lessons we have learned.

1. Align \& balance the needs of students and clients. For the most part, the pedagogical goals of the course align strongly with what the clients want. Occasionally, however, clients will request services that go beyond what student teams can deliver. In one case, for example, a small company wanted help advocating for changes in a certain quality standard that affected the labeling of its products. In some cases, too, entrepreneurs have asked students to essentially start selling their early-stage products. Tasks like these fall outside the domain of the course. In these cases, faculty coaches can help keep projects on track, and sometimes coaches can suggest alternative sources of help to clients. It helps, too, if the team drafts a clear "Statement of Work" early in the term in collaboration with its coach and client. Finally, be aware that clients differ in how extensively they want to be involved in their projects. Some clients like to attend meetings regularly and to interact often with student teams, whereas others prefer to meet and communicate just a few times each term. We give clients wide latitude to set the terms of their involvement. It can help for teams to designate one or two members as client liaisons to keep communication efficient.

2. Support teamwork. Teamwork can be challenging, whether in the workplace or the classroom. To help teams run smoothly, we begin the year with a session devoted to "team-building" exercises designed to encourage trust, collaboration and communication. For example, we ask teams to quickly write and perform a skit that illustrates their product. This prompts teams to inject laughter and humor into their work routines, and, as Prof. Barry Kudrowitz of our College of Design has found, this can actually help groups to be more creative later on. We also require teams to agree to some "team rules" early in the year. Throughout the term, coaches and instructors revisit key points of effective teamwork to ensure that teams fully harness their members' individual strengths and manage the conflicts that inevitably arise. For example, we remind teams that "task-based conflict" can be healthy to a point but that "relationship conflict" is always detrimental to team outputs. We also remind students that managing complex projects and project relationships is part of the new product design process and that learning to manage these challenges is part of their education.

\section{Be mindful of the needs of different student}


groups. Many engineering students are full-time students, but many MBA students are part-time students. Over time, therefore, we've taken steps to make the course more accessible to part-time MBA students. First, we have allowed MBA students to take the course for just one term instead of both terms. The reason is that MBA students often have less room in their schedules to commit to the course for an entire year. This creates some "team turnover" in January of each year, but this enhances the realism of the experience, since many workplace teams also experience turnover. In addition, we schedule the course in an evening time slot to accommodate the needs of working students. Virtual meetings, delegation, and asynchronous work schedules enable these heterogeneous teams to get work done with relatively few in-person meetings.

4. Build failure into the learning process. New product development is inherently hard, and failure is common even in seasoned corporate $R \& D$ departments -- so it happens in this class too. We always look for ways to persist and learn in the face of adversity, but we don't want to shield students or clients from failure when it occurs. Small-scale failures occur when design features prove technically infeasible or are summarily rejected by prospective customers, and most teams experience enough such failures to require them to pivot several times during a project. Larger-scale failures occur when a project runs an entire year and the accumulated data point strongly to the conclusion that a given product is very unlikely to be a financially viable investment. In these cases, we encourage students to present their data and analyses honestly to clients, even though the client may be disappointed by the news. Even these clients derive value from the program by being able to terminate or redirect a project before larger, longer-term investments are made.

5. Leverage faculty leadership. Cross-campus initiatives require some support from deans and other administrators, but they also require passionate engagement from "front-line" faculty in each of the participating units. Our course has benefited from having a set of faculty in engineering and business who all find the course intellectually and professionally rewarding. It also helps that over the years the faculty roster has included a mix of "veterans" and "newcomers," whose experiences provide a mix of hardearned wisdom and fresh insight. Finally, all the faculty involved should understand that new product development is a complex, multifaceted domain and that no one can be an expert in every part of it. Awareness of this fact has helped our faculty maintain a sense of mutual respect and curiosity over the years.

Some additional observations are available in this article (http://www.sciencedirect.com/science/article/pii/S0737 678201001163 ), which was published in 2002 in the Journal of Product Innovation Management.

\section{Conclusion}

Courses like NPDBD don't necessarily need to displace more traditional entrepreneurship courses, such as survey courses or topic-focused courses (e.g., those focused on new venture finance). In fact, more traditional courses often represent an important foundation for or complement to experiences like NPDBD. However, cross-campus and experiential offerings can expand and enrich the way schools deliver entrepreneurship education. We hope the experiences we've described here can be of use to faculty, staff and others who may want to establish or modify similar courses in their own schools.

Additional Search Terms: entrepreneurship courses, teaching ideas, teaching resources, classroom ideas, entrepreneurship classes, business schools, business school classes, entrepreneurship students, professors 